\title{
Single-blind placebo-controlled response on phenytoin $10 \%$ in painful diabetic neuropathy
}

\author{
Jan M Keppel Hesselink* \\ Institute for Neuropathic Pain, Spoorlaan 2a, 3735 MV, Bosch en Duin, The Netherlands
}

\begin{abstract}
Phenytoin is a broad acting sodium channel blocker, with analgesic properties in animal models and in controlled human clinical trials. The pathogenesis of Painful Diabetic Neuropathy is partly located in the skin, based on the peripheral sensitization of nociceptors and small nerve fibers. We developed a topical formulation of $10 \%$ phenytoin cream to treat those patients. Here we describe a classical patient suffering from peripheral symmetrical Painful Diabetic Neuropathy, treated successfully with this cream. We evaluated whether this patient was a responder by applying a placebo-controlled single-blind response test. Pain was reduced from NRS-score 7 to 5 by placebo and from 7 to 0 by phenytoin cream. Based on this positive response test, phenytoin $10 \%$ cream was prescribed.
\end{abstract}

\section{Introduction}

Pain treatment in patients suffering from peripheral neuropathic pain is still not optimal. Over half of all patients treated with gabapentin will not have clinical relevant pain relief and may experience adverse events [1]. The evidence of benefit from tramadol is of low quality, and tramadol seems not to provide a likely effect [2]. The same holds true for morphine, oxycodone and nortriptyline [3-5]. Topical high dose of capsaicin helps only in a small number of patients, the Number Needed to Treat is around 8 [6]. Clearly there still is a great unmet need in this indication, and there are not many promising new chemical entities (NCE's) in the pipeline. Some drugs which led to high expectations during early development, recently failed in phase II and III development. Moreover, there are a great number of stumbling blocks in the development of NCE's in neuropathic pain [7-9]. Repurposing old drugs in the field of neuropathic pain therefore is an intriguing option which needs to be evaluated, and phenytoin is an old drug with a clear repurposing profile [10].

\section{Case presentation and response to test paradigm}

We present a 71-year old female patient, suffering from Painful Diabetic Neuropathy since 2000. Medical History: 2005 a bipolar depressive disorder, 2013 atrial fibrillation, 2014 erythema nodosum, vulvodynia, ischialgia, and in 2015 a transient ischemic attack. Medication: tranylcypromine $20 \mathrm{mg}$ daily, lithium $500 \mathrm{mg}$ daily, metformin $850 \mathrm{mg} 2 \mathrm{dd} 1$, glimepiride $2 \mathrm{mg} 2 \mathrm{dd} 1$, sotalol $40 \mathrm{mg} 3 \mathrm{dd} 1$, apixaban $5 \mathrm{mg} 2 \mathrm{dd} 1$, simvastatin $20 \mathrm{mg} 2 \mathrm{dd} 1$, psyllium powder, oxazepam $10 \mathrm{mg}$ on a as needed base. Previous pain medication pregabalin did not result in sufficient satisfactory effects.

The pain was located symmetrical at both feet up to $10 \mathrm{~cm}$ above ankles, and the pain characteristics were: pins and needles, tingling, and numbness.

On physical examination, we found classical hypo-esthesia for pin prick and touch, but no signs of allodynia. Baseline pain score on the 11-points Numeric Rating Score NRS before application of cream was 7. The DN-5 score was 5 , supporting the diagnosis of neuropathic pain.
Phenytoin cream reduced the pain score from 7 to 0 , while placebo cream reduced the pain with 2 points only.

\section{A single blind placebo-controlled test paradigm}

This patient qualified for a single-blind response test. We developed this new test paradigm to quickly evaluate whether patients are responders to phenytoin cream, or placebo responders (Figure 1).

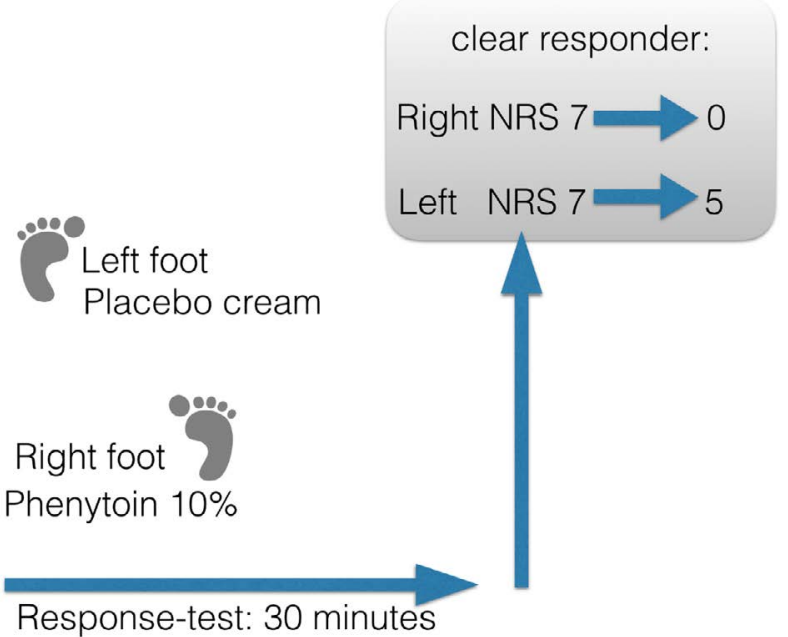

Figure 1. Single Blind Responder Test: phenytoin 10\% cream was applied on the right foot, and placebo cream on the left foot. Patient was not aware of the difference, but the treating physician was (single blind). The pain reduction after placebo cream application on the left foot was 2 points on the NRS, from a pain score of 7 to 5 , and for the phenytoin $10 \%$ cream applied on the right foot, the pain was reduced from a NRS score of 7 to 0 .

${ }^{\star}$ Correspondence to: Jan M Keppel Hesselink, Institute for Neuropathic Pain, Spoorlaan 2a, 3735 MV, Bosch en Duin, The Netherlands, Tel: 31628671847; E-mail: info@neuropathie.nu

Received: February 08, 2018; Accepted: February 23, 2018; Published: February 26, 2018 
The response test can only be used in case of a symmetrical distribution of pain in left and right foot, or in cases of a big surface of pain, for instance as in Postherpetic Neuralgia or meralgia paresthetica. We prefer the test in cases where it is obvious that the pathogenesis is at least partly residing in the skin compartment, such as in PDN and Small Fiber Neuropathy.

The Single Blind Responder Test is easy to conduct. When we started treating with topical phenytoin cream, patients informed us that the pain quickly was reduced after application, mostly within 15 minutes. This provoked us to develop this test. We could apply the test within the context of the first visit of a new patient to our clinic. During the first visit patients have many questions, and the visit takes quite some time. We explain the test relatively early during the visit in order to able to apply the test during the visit. By following this approach, we mostly know at the end of the first consultation whether the patient is a responder to the phenytoin cream, or a placebo responder. Alternatively, patients can be tested after the consultation and return to the waiting room for 15-30 minutes. Thereafter we see the patients again and we evaluate the effects.

In this case pain in both feet was comparable. If there is more than 1-point difference in pain score between left and right, we feel the test is not optimal enough. We applied the phenytoin $10 \%$ cream on the right foot, and placebo cream on the left foot. Patient was not aware that a placebo cream was applied, but the physician was (single-blind). We used the following explanation: "We will treat your pain with 2 creams, and you are going to decide which cream works best. From one cream, we do not exactly know how that cream reduces pain, for the other cream we have a good idea about the mechanism." In this way, we have made transparent that both creams might work, which is the reality, both for the active as for the placebo cream.

In the presented case, the pain reduction after placebo cream application on the left foot was 2 points on the NRS, from a pain score of 7 to 5 , and for the phenytoin $10 \%$ cream applied on the right foot, the pain was reduced from a NRS score of 7 to 0 .

\section{Discussion and preview}

This case is an example of many patients we treated to date with phenytoin cream (more than 100). Meanwhile we have reported a number of these cases [11-15]. In 16 patients, we analyzed the plasma, and levels of phenytoin were below the limit of detection. This, together with the quick onset of action supports an intra-epidermal mechanism of action. Phenytoin is one of the oldest active pharmaceutical ingredient acting as a broad acting sodium channel blocker and is regarded as a one of the first discovered anticonvulsants. Phenytoin is still used as a golden standard drug during the quest for new and better anticonvulsants [16]. Phenytoin is also presented as a golden standard for neuropathic pain treatment and for lead optimization in animal models for pain. [17] It is hypothised that the mechanism of action is based on its capacity to inhibit sodium channels in nociceptors, as well as in other cell compartments in the epidermis, which cross-talk to the nociceptors (Figure 2) [18].

Initially we prescribed phenytoin cream without using a test paradigm. However, soon we felt the need to identify responders in order to individualize and optimize treatment. We started using an open response test, where we applied phenytoin cream only on one foot, and asked the patient to compare the pain after 10-30 minutes between the treated and the untreated foot. Clearly by following such approach there is room for placebo-response. Indeed, sometimes patients complained during a follow-up visit that the pain-reducing effect did not last long enough and after some days they felt no effect

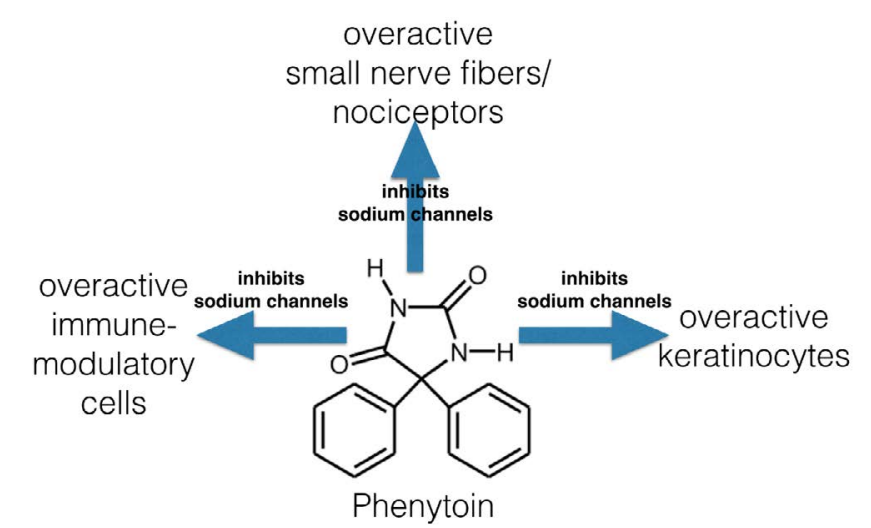

Figure 2. The mechanism of action of phenytoin: inhibiting sodium channels in the nociceptors and in other epidermal cellular compartments

anymore. This was a reason why we started testing active and placebo cream simultaneously, in case of a symmetrical painful neuropathy.

Meanwhile we consider the further development of the test from a single-blind design to a double-blind design, in order to rule out our own influence as prescribing physicians during the test. We feel this is not a step which deviates from our normal practice of testing, but it would optimize the responder identification even more. The doubleblind response test can be explicitly further developed in order to be able to even more optimally select responders and exclude non-responders and placebo-responders compared to the single-blind responder test. Thus, it will contribute to the individualization of therapy.

Phenytoin cream is a repositioned new topical formulation of an old drug. To date we did not detect troublesome side-effects, and in many patients suffering from peripheral neuropathic pain, as we reported in previous articles, pain reduction is considerable, and the onset of action is quick.

\section{Conflict of interest}

The author is one of the patent holders of two patents related to the topical formulations of phenytoin in the treatment of pain:

- Topical phenytoin for the use in the treatment of peripheral neuropathic pain, and

- Topical pharmaceutical composition containing phenytoin and a (co-)analgesic for the treatment of chronic pain.

\section{References}

1. Wiffen PJ, Derry S, Bell RF, Rice AS, Tölle TR, et al. (2017) Gabapentin for chronic neuropathic pain in adults. Cochrane Database Syst Rev 6: CD007938 [Crossref]

2. Duehmke RM, Derry S, Wiffen PJ, Bell RF, Aldington D, Moore RA (2017) Tramadol for neuropathic pain in adults. Cochrane Database Syst Rev 6: CD003726 [Crossref]

3. Cooper TE, Chen J, Wiffen PJ, Derry S, Carr DB, et al. (2017) Morphine for chronic neuropathic pain in adults. Cochrane Database Syst Rev 5: CD011669 [Crossref]

4. Gaskell H, Derry S, Stannard C, Moore RA (2016) Oxycodone for neuropathic pain in adults. Cochrane Database Syst Rev 7: CD010692 [Crossref]

5. Derry S, Wiffen PJ, Aldington D, Moore RA (2015) Nortriptyline for neuropathic pain in adults. Cochrane Database Syst Rev 1: CD011209.

6. Derry S, Rice AS, Cole P, Tan T, Moore RA (2017) Topical capsaicin (high concentration) for chronic neuropathic pain in adults. Cochrane Database Syst Rev 1: CD007393 [Crossref]

7. Keppel Hesselink JM (2017) Arguments to develop TRPV1 antagonist in neuropathic pain. Lessons for drug development. Clinical Research and Trials (CRT) DOI: 10.15761/CRT.1000165 
8. Keppel Hesselink JM (2017) NS1209/SPD 502, A Novel Selective AMPA Antagonist for Stroke, Neuropathic Pain or Epilepsy? Drug Development Lessons Learned. Drug Dev Res doi: 10.1002/ddr.21376 [Crossref]

9. Keppel Hesselink JM (2017) Moving targets in sodium channel blocker development: the case of raxatrigine: from a central NaV1.3 blocker via a peripheral NaV1.7 blocker to a less selective sodium channel blocker. $J$ Med Therap 1:1-3

10. Keppel Hesselink JM (2017) Amantadine and phenytoin: patent protected cases of drug repositioning. Clin Invest. 7: 11-16.

11. Keppel Hesselink JM, Kopsky DJ (2017) Topical phenytoin cream in small fiber neuropathic pain: fast onset of perceptible pain relief. Int J Pain Relief 1: 15-19.

12. Kopsky DJ, Keppel Hesselink JM2 (2017) Topical phenytoin for the treatment of neuropathic pain. J Pain Res 10: 469-473 [Crossref]

13. Keppel Hesselink JM, Kopsky DJ (2017) Phenytoin cream reduces pain and improves sleep in patients suffering from neuropathic pain. Austin J Anesthesia and Analgesia 5: 1061.
14. Keppel Hesselink JM, Kopsky DJ (2017) Topical phenytoin cream reduces burning pain due to small fiber neuropathy in sarcoidosis. J Anesth Pain Med 2: 1-3.

15. Keppel Hesselink JM, Kopsky DJ (2017) Pain in chemotherapy induced peripheral neuropathy treated with topical phenytoin cream. CP Cancer Sci 1: 008.

16. Wu HF, Han RB, Jin CZ, Piao FY1 (2016) Synthesis of Novel 8-alkylamino-5, 6-dihydro-4H-benzo[f] [1,2,4] triazolo [4,3-a] azepines as Anticonvulsant Agents. CNS Neurol Disord Drug Targets 15: 1333-1343 [Crossref]

17. de Queiroz RB, de Carvalho FL, Fonsêca DV, Barbosa-Filho JM, Salgado PR, et al. (2015) Antinociceptive effect of hydantoin 3-phenyl-5-(4-ethylphenyl)-imidazolidine2,4-dione in mice. Molecules 20: 974-986 [Crossref]

18. Keppel Hesselink JM, Kopsky DJ, Bhaskar AK (2016) Skin matters! The role of keratinocytes in nociception: a rational argument for the development of topical analgesics. J Pain Res 10: 1-8 [Crossref]

Copyright: (O2018 Hesselink JMK. This is an open-access article distributed under the terms of the Creative Commons Attribution License, which permits unrestricted use, distribution, and reproduction in any medium, provided the original author and source are credited. 